Perceived authenticity of traditional branded restaurants (China): impacts on perceived quality, perceived value, and behavioural intentions

Chen, $\mathrm{Q}$

http://hdl.handle.net/10026.1/16153

10.1080/13683500.2020.1776687

Current Issues in Tourism

Informa UK Limited

All content in PEARL is protected by copyright law. Author manuscripts are made available in accordance with publisher policies. Please cite only the published version using the details provided on the item record or document. In the absence of an open licence (e.g. Creative Commons), permissions for further reuse of content should be sought from the publisher or author. 
Perceived authenticity of traditional branded restaurants (China): impacts on perceived quality, perceived value, and behavioural intentions

Key words: perceived authenticity, perceived quality, traditional branded restaurants, consumers' dining experiences

\section{Author Details:}

1.Dr. Qian Chen* Yangzhou University, China (Corresponding author*)

School of Tourism and Cuisine, Yangzhou University, Yangzhou, China

Address: 196 Huayang West Avenue, Yangzhou, China

Tel.: +8618796669711

Email address: qian.chen@yzu.edu.cn

qianchen0303@outlook.com

2. Dr. Rong Huang Plymouth University, UK

School of Tourism and Hospitality, Plymouth University, Plymouth, UK, PL4 8AA

Tel.: +4401752232836

Email: rong.huang@plymouth.ac.uk

3. Prof. Bing Hou Yangzhou University, China

School of Tourism and Cuisine, Yangzhou University, Yangzhou, China

Email: bhou@yzu.edu.cn

Funding: This work was supported by the National Natural Science Foundation of China under Grant 41771146, the Philosophy and Social Science Foundation of Jiangsu Higher Education Institutions under Grant 2018SJA1126, and the Yangzhou University Qing Lan Project. 


\title{
Perceived authenticity of traditional branded restaurants (China): impacts on perceived quality, perceived value, and behavioural intentions
}

\begin{abstract}
This study attempts to investigate the perceived authenticity of consumers in Chinese traditional branded restaurants, as well as to investigate the specific factors that contribute to consumers' perceived authenticity. It constructs a systematic model addressing whether, and how, consumers' perceived authenticity, can influence their behavioural intentions through perceived quality of food, service, and dining environment, as well as perceived values in traditional branded restaurants. Results were derived from a mixed-method approach where 68 consumers were initially interviewed, followed by interviewer-administered questionnaire survey with additional 418 consumers. Qualitative analysis, along with exploratory factor analysis and confirmatory factor analysis confirmed five factors that influencing consumers' authenticity perceptions: historical and cultural value, brand value, nostalgia, environment authenticity, and food authenticity. Structural equation modelling analysis revealed positive impacts of consumers' perceived authenticity and perceived service quality on their perceived value of dining experience, which in turn predict consumers' behavior intentions.
\end{abstract}

Key words: perceived authenticity, perceived quality, traditional branded restaurants, consumers' dining experiences

\section{INTRODUCTION}

The last few decades witnessed the growing quest for authenticity in consuming products and services (Gilmore \& Pine, 2007). Authenticity thus has been thus increasingly utilised by marketers as a significant marketing strategy in the tourism and hospitality industries (Kim \& Boon, 2016; Ramkissoon \& Uysal 2011). In particular, Lin, Ren and Chen (2017) noted that the authenticity factor is more influential in highlighting food or cuisine as ambassadors of culture and tourism. The 
number of consumers demanding authentic food experiences is on the increase (Beer, 2008; Sims, 2009). More and more diners are viewing authenticity as one of the most significant criteria selecting restaurants (Oum, 2005).

Authenticity, in relation to identity, nostalgia, and historic roots, has become a unique selling point and a value-added offering for restaurants (Kovács, Carroll, \& Lehman 2014; Lu, Gursoy, \& 2015; Molz, 2013). According to Chhabra, Lee, Zhao, and Scott (2013), authenticity of restaurants is much shaped through the consumers' own perceptions as it is decided by the performance of the host. Consequently, a number of studies (Jang, Ha, \& Park, 2012; Lu et al., 2015; Liu, Liu, DiPietro, \& Levitt, 2018; Wang \& Mattila, 2015) have noted the significance of understanding consumers' perceived authenticity in assisting restaurants to sustain and construct authenticity. In particular, many studies have acknowledged the positive association between consumers' authenticity perceptions of ethnic restaurants and perceived quality (Lu et al., 2015), perceived value (Kovács et al., 2014; Liu et al., 2018), and behavioural intentions (Kim et al., 2017; Wang \& Mattila, 2015).

However, only a few studies (DiPietro \& Levitt, 2019; Jang et al., 2012; Liu et al., 2018) have thoroughly investigated the relationships among consumers' authenticity perceptions, quality judgements, value assessment, and behavioural intentions at the same time. Specifically, Jang et al. (2012) examined the effects of consumers' perceived authenticity at a Korean restaurant in the United States. DiPietro and Levitt (2019) assessed consumers' perceptions of authenticity at regional American-style restaurants. Liu et al. (2018) investigated the role of consumers' perceived authenticity at an Italian restaurant in southeastern USA. Those studies have all confirmed the significance of authenticity in influencing the behavioural intentions of consumers. However, it is noted that most of the research attention has been focused on the ethnic restaurants in the Western context (DiPietro \& Levitt, 2019; Jang et al., 2012; Liu et al., 2018) with limited research concerning consumers' perceived authenticity of restaurants in the Chinese context. 
It is significant to examine consumers' perceived authenticity of restaurants in the Chinese context for the following reasons. First of all, the diversity, flexibility, and adaptability of the Chinese food culture developed throughout history justify the reputation of China as a food paradise (Chen \& Huang, 2018). From the distant past to the present, Chinese people are featured as having a food-centred culture that few other cultures are as food oriented as the Chinese (Chang, 1977). Given the great passion that Chinese people show towards food, more and more domestic tourists in China are seeking culinary pleasures during their travel (Chen \& Huang, 2016, 2019). Many scholars (Cheng, Hu, Fox, \& Zhang, 2012; Chen \& Huang, 2018, 2019) thus have highlighted the huge potential of the continual development of the food tourism market in China, which also responded to consumers' increasing desire for authentic dining experience as addressed below.

Authenticity is an important element in building up brand experience (Atwal \& Williams, 2012). In China, there have been a group of restaurants with a consistent honorary title 'China Time-honored Brand' awarded by the Ministry of Commerce of the People's Republic of China (Ma, Wei, \& Bai 2017; Xu, Wang, Wang, \& Song, 2015). Time-honoured brand, known as traditional brand, is a brand with a history of over 50 years and features unique inherited products, skills or services passed down from generation to generation (Xu \& Feng, 2018). With distinctive historical and cultural value, traditional brand enjoys a good reputation as well as a wide recognition by the community (Xu et al., 2015). Therefore, these restaurants were simply named 'traditional branded restaurants'. The traditional branded restaurants in each area/city reflect the regional cultural characteristics of China (Xu \& Feng, 2018). With most of their craftsmanship being recognized as the country's intangible cultural heritage, traditional branded restaurants represent traditional culture, historical heritage, exquisite skills, reasonable price, good quality, and reliability in the minds of consumers (Ma et al., 2017). 
However, with the development of economic globalisation, the growing popularity of western fast food culture and the changes of consumers' dietary habits have been requiring the traditional branded restaurants to be more modernised and innovative to retain brand value and market recognition (Xu et al., 2015). In order to meet the market demand and consumers' taste, many traditional branded restaurants have been focusing on catching up with fashionable trends while resulted in neglecting the inheritance of traditions (Ma, Wei, \& Bai, 2017; Xu \& Feng, 2018). It is noted that many traditional branded restaurants are growingly losing its authenticity in terms of product development, brand culture, and brand experience throughout the development (Xu et al., 2015). Nevertheless, despite the development of western food culture, the actual demand from consumers for Chinese cultural consumption is on the increase that more and more consumers are seeking to obtain authentic cultural experience through dining at Chinese traditional branded restaurants (Ma et al., 2017).

Consequently, how to sustain and construct authenticity has become the key proposition for traditional branded restaurants to respond to the consumers' desire for authentic experience (Wang \& Wang., 2014). This study aims to examine the perceived authenticity of consumers in Chinese traditional branded restaurants. More specifically, the following research objectives are sought as listed below:

(1) To investigate the specific factors that contribute to consumers' perceived authenticity in Chinese traditional branded restaurants;

(2) To assess the impacts of consumers' perceived authenticity on their perceived quality, perceived value, and behavioural intentions in Chinese traditional branded restaurants;

(3) To recommend how to sustain and construct the authenticity of traditional branded restaurants.

This study contributes to the existing literature in the following aspects. Firstly, this study responds to the existing gap in the literature by testing the direct relationship between perceived authenticity and behavioural intentions in the restaurant sector. It 
shed light on examining whether consumers' perceived authenticity can directly influence their behavioural intentions. Secondly, this study adds to the understanding of consumers' perceived authenticity at Chinese traditional branded restaurants through investigating the specific influential factors. In addition to the two commonly identified factors (i.e food authenticity and environment authenticity), this study confirmed three additional factors that could influence consumers' perceived authenticity. Thirdly, through examining the authenticity of traditional branded restaurants, it not only extends the research on restaurant authenticity to more varied contexts, but also benefits traditional branded restaurants in developing more effective marketing strategies.

\section{LITERATURE REVIEW}

\subsection{Authenticity}

According to Cappannelli and Cappannelli (2004), the word "authenticity" is derived from the Latin word authenticus and the Greek word authentikos representing the sense of trustworthiness. It is used to describe something that is genuine, original, innocent, sincere, honest and unaffected (Fine, 2003). Although many researchers (Grayson \& Martinec, 2004; Holt, 2002) have attached associations and denotations to the term, there is still no agreement formed on the unique definition of authenticity (Bruhn et al., 2012). Nevertheless, a number of researchers contributed to the understanding of authenticity through identifying three different dimensions: objective, constructive, and existential (Alexander, 2009; Lu et al., 2015). In particular, the objectivist perspective sees authenticity as an object's origin or expert evaluations (MacCannell, 1973). The constructive perspective refers to a projection of one's own beliefs, expectations, and perspectives, which is largely staged and negotiated (Cohen, 1988; Wang, 1999). The existential dimension is related to the experience of consumer, examining authenticity as being true to one's self (Jamal \& Hill 2004; Wang, 1999).

In 2004, Grayson and Martinec introduced the concepts of indexical and iconic 
authenticity that the indexical authenticity refers to the real and original thing but not an imitation, while iconic authenticity refers to something extremely similar or close to the original. According to Grayson and Martinec (2004), authenticity is better understood as an assessment made by a particular evaluator in a particular context. They highlighted that both authenticity and inauthenticity are a result of how individuals perceive and interpret objects and expressions (Grayson \& Martinec, 2004), which supported a number of studies (Robinson \& Clifford, 2012; Wang \& Mattila, 2015; Wood \& Munoz, 2006) indicating authenticity perceptions of the same restaurant may vary among consumers. Additionally, with particular concern to the context of Chinese food, Lu and Fine (1995) noted that the authenticity of Chinese food lies in the eyes of the beholder. Consequently, this paper focuses on consumers' constructive authenticity of Chinese traditional branded restaurants, i.e perceived authenticity.

\subsection{Perceived authenticity, perceived value and behavioural intentions}

There is extant research noting a significant role of perceived authenticity on consumer behaviour (Liu et al., 2018; Fu et al., 2018; Tsai \& Lu, 2012). In particular, many marketing managers and researchers have reported the positive relationship between perceived authenticity, perceived value and behavioural intentions within the tourism and hospitality contexts (Fu et al., 2018; Jang et al., 2012; Kim \& Bonn, 2016; Liu et al., 2018).

Perceived value refers to a consumer's assessment of the net worth of a product based on the comparison between the perceived sacrifices with the overall benefits received (Lovelock, 2000; Zeithaml, 1988). It has been recognised as one of the most significant concepts for understanding customers in the service industry (Ha \& Jang, 2010; Zeithaml, 1988). Perceived value can be divided into two dimensions: functional value and affective value (Lin \& Wang, 2012; Sánchez et al., 2006; Sweeney \& Soutar, 2001). The functional value is concerned with the quality of product and service, as well as consumers' monetary valuations, while affective value 
relates to the feelings and emotions generated by the touristic experience (Sánchez et al., 2006; Sweeney \& Soutar, 2001). Empirically, a number of researchers have acknowledged the positive impacts of perceived value on customer satisfaction and behavioural intention (Ha \& Jang, 2010; Jang et al., 2012; Ryu, Han, \& Jang, 2010).

According to Kovács et al. (2014), consumers tend to perceive more values of restaurants that were perceived more authentic. Researchers found that perceived authenticity positively influence consumers' perceived value and consequent lead to higher behavioural intentions. Jang et al. (2012) noted the effects of authenticity on customers' perceived values and behavioural intentions when investigating Korean restaurant in the U.S. Liu et al. (2018) confirmed the effects of perceived authenticity on diners' perceived value, which in turn predicts diners' behavioural intentions at an independent full-service Italian restaurant. However, whether these findings are applicable to the context of Chinese traditional branded restaurants remains uncertain.

In addition, although the relationship between perceived authenticity and perceived value, and the relationship between perceived value and behavioural intentions have been well investigated in the restaurant sector, whether perceived authenticity can be a direct antecedent to behavioural intentions has been rarely studied. Nevertheless, given a number of studies in the broader tourism and hospitality contexts (Fu et al., 2018; Kim \& Bonn, 2016; Muskat et al., 2019; Ramkissoon \& Uysal, 2011), a significant positive relationship has been supported between perceived authenticity and behavioural intentions of tourists.

Consequently, the following hypotheses are proposed:

H1: Consumers' authenticity perception positively influences their perceived value at traditional branded restaurants.

H2: Consumers' perceived value positively influences their behavioural intentions at traditional branded restaurants. 
H3: Consumers' authenticity perception positively influences their behavioural intentions at traditional branded restaurants.

\subsection{Perceived authenticity \& perceived quality}

Authenticity is viewed as a critical factor in examining the quality and value of tourism products and experience (Akhoondnejad, 2016; Kim \& Jamal, 2007). However, Liu et al. (2018) argued that the relationship between perceived authenticity and perceived quality in previous literature is ambiguous. In particular, Kovács et al.'s (2014) study noted perceived authenticity and perceived quality are distinct constructs creating value separately. Nevertheless, consumers may use authenticity to convey quality assessment of the restaurants (Kovács et al., 2014; Liu et al., 2018). Lu et al. (2015) found consumers' perceived authenticity is a predictor of perceived quality, and confirmed the positive impacts of perceived authenticity on perceived quality in ethnic restaurants. Zhang, Chen and $\mathrm{Hu}$ (2019) concerned the traditional view of quality attributes, and argued that authenticity is a strong predictor to the quality-satisfaction-loyalty framework of food tourism. Moreover, Akhoondnejad (2016) and Robinson and Clifford (2012) found in the context of a local festival that consumers' perceived authenticity influenced perceived quality, value and satisfaction.

Thus, the following hypothesis was proposed:

H4: Consumers' perceived authenticity positively influences their perceived quality at traditional branded restaurants.

\subsection{Perceived quality, perceived value and behavioural intentions}

Parasuraman, Zeithaml, and Berry (1988) defined that perceived quality refers to the gap identified from customer expectations and their perceptions of the actual performance of the organization. In particular, Muskat et al.(2019) noted that the assessment of consumers' perceived quality is formed through a recall of various aspects of the overall experience. In order to more accurately assess the role of 
perceived quality in the dining experience, following the suggestions by Liu et al. (2018) and Muskat et al. (2019), quality of food, physical environment, and service were identified as the relevant aspects consisting the overall assessment in this study.

Food, restaurant environment, and the employee service are the three most significant features of a restaurant (Jang et al., 2012; Jang \& Namkung, 2009). Extant studies have shown the quality of food, physical environment, and service as important antecedents of perceived value and behavioural intentions in the restaurant setting (Ha \& Jang, 2010; Liu \& Tse, 2018; Muskat et al., 2019; Ryu, Lee, \& Kim, 2012). In particular, food quality is well accepted as one of the key factors leading to customers' satisfaction and post-dining behavioural intentions in the restaurant industry (Kim, Youn, \& Rao, 2017). Empirically, Jang et al. (2012) and Ryu et al. (2012) noted that high quality of food leads to a higher perceived value of the dining experience. Ha and Jang (2010) acknowledged the direct correlation between food quality and behavioural intentions in casual dining ethnic restaurants.

According to Russell and Ward (1982), physical environment influences human behaviour in environmental psychology research. Environment was thus increasingly utilised as a significant marketing tool (Kotler, 1973). Lee and Whaley (2018) found that physical environment and food quality are the strongest predictors of customer dining satisfaction and behavioural intentions. Han and Ryu (2009) and Liu and Jang (2009) highlighted the direct effects of restaurant's physical environment on restaurant's image and customers' perceived value, which in turn affects consumers' behavioural intentions. Additionally, perceived service quality mainly relies on the relationship between customers and service providers and an employee's performance (Nikolich \& Sparks, 1995). According to Lin, Chan and Tsai (2009), service quality contributes to a firm's success through influencing consumers' behavioural intentions and loyalty. Based on the overall literature, consumers' perception of service quality in the restaurant setting is highlighted in positive relationship with consumer perceived value (Eggert \& Ulaga, 2002; Jang et al., 2012), and behavioural intentions 
(Ha \& Jang, 2010; Muskat et al., 2019)

Therefore, based on the above discussion, the study hypothesizes that:

H5. Consumers' perceived quality (food, physical environment, and service) positively influences their perceived value of traditional branded restaurants.

H6. Consumers' perceived quality (food, physical environment, and service) positively influences their behavioural intentions at traditional branded restaurants.

Figure 1 below presents the theoretical model of the hypothesised relationships among variables including the quality of food, environment, service, perceived authenticity, perceived value, and behavioural intentions.

\section{Please Insert Figure 1.}

\subsection{Study context}

This paper focuses on Yangzhou, a historic and cultural city in China with more than 2500 years' history. China enjoys a vast and varied landscape, as well as a vast variety of cuisines (Chang, 1977). As the 'Hometown of Huaiyang cuisine', one of the four major traditional cuisines in China, Yangzhou boasts abundant food resources, profound food culture, and rich food-related intangible cultural heritage (Hou, Tao, \& Chen, 2016). Huaiyang cuisine has been enjoying a great reputation for its simple ingredients, original taste, and excellent cooking skills (Li, Hou, \& Xu, 2019). Kim et al. (2017) mentioned that cuisine from other regions or cities in China could appeal to domestic tourists as unique and sometimes exotic characteristics. Therefore, tasting the local Huaiyang cuisine has become an inevitable choice for both domestic and international tourists visiting Yangzhou (Hou et al., 2016). As the representative vividly introduces the history and culture of Huaiyang cuisine, traditional branded restaurants in Yangzhou are not only important catering brands but also a city card of Yangzhou (Yan \& Zhang, 2017). Its formation has gone through hundreds of years, 
and it is also the epitome of urban history and culture.

\section{METHODOLOGY}

This study adopted a two-stage mixed methods approach combining both qualitative

and quantitative methods (Creswell \& Clark, 2011; Teddlie \& Tashakkori, 2009). According to Creswell and Clark (2011), the use of quantitative and qualitative methods in combination provides a better understanding of research problems with the weaknesses of one method offset by the strengths of the other method. It is often acknowledged that a mixed methods approach is a way to improve the validity and utility of findings (Hewlett \& Brown, 2018).

In this study, a sequential explanatory design was utilized with a qualitative method used as the initial mode of enquiry, followed by a quantitative method. The purpose of the initial qualitative phase is to explore factors that influence consumers' authenticity of the dining experience in Chinese traditional branded restaurants given the fact that there were few studies examining authenticity in the context of Chinese traditional branded restaurants. This exploratory qualitative phase gave rise to the underlying factors of consumers' perceived authenticity which are then tested in the quantitative phase.

\subsection{Phase 1: qualitative method}

\subsubsection{Data collection}

The main technique for obtaining qualitative information was semi-structured in-depth interviews with open-ended questions. The target population of this study were consumers who had experience with traditional branded restaurants in Yangzhou, China. In particular, they were mainly asked two questions: what motivated their visit and what attributes influenced an authentic dining experience at a traditional branded restaurant. There were two well-recognized traditional branded restaurants (i.e Fuchun teahouse and Gong hechun teahouse) enjoying the title of 'China 
Time-honored Brand' in Yangzhou. Therefore, potential respondents should either had dined at Fuchun teahouse or Gong hechun teahouse. In order to gather varied opinions, purposive sampling was utilized with the deliberate selection of different subgroups (such as consumers from Fuchun and Gonghechun, male and female, etc). The date collection process terminated when saturation was achieved in the data, and there was no new information derived from the interviewees (Lin et al., 2017).

In terms of the data collection process, interviewees were approached and invited for interviews at the reception areas of restaurants when they finished their dining. They were invited to freely share their dining experiences and express their opinions, suggestions and concerns on the attributes or influencing factors of their perceived authenticity of the dining experience at traditional branded restaurants. In total, 68 interviews were conducted in November 2018 with consumers who dined at Fuchun teahouse or Gong hechun teahouse in Yangzhou. With the target of the interviewees determined as domestic consumers, the interviews were conducted in Mandarin Chinese. Then, the transcripts were translated into English using a back-translation approach prior to analysis. The profiles of the interviewees are provided in the appendix.

\subsubsection{Data analysis}

Thematic analysis was adopted to analyse the qualitative data (Braun \& Clarke, 2006). According to Wells, Manika, Gregory-Smith et al. (2015), thematic analysis assisted the identification of themes from interviewees' narratives. Therefore, the interviews were recorded and transcribed, which were then analyzed and coded manually using a grounded analysis technique (Dayour, Park, \& Kimbu, 2019). The analysis process involves four main steps. Firstly, the reviews were read and familiarized to generate an overall understanding of customers' dining experience. Secondly, the data were broken down into distinct units of meaning, and an initial set of code was identified. In order to ensure consistency, clarity and objectively of the coding process, two researchers were involved (Thomas, 2006). In case with no agreement between the 
two researchers, a third person was called upon to express his/her opinion. Table 1 below presents the examples of opening coding process. Thirdly, axial coding process was conducted to organize the coded data into different themes or categories (Creswell, 2007). Lastly, selective coding was followed to understand the context, interactions, and consequences of the categories with the review of the literature. The results are presented and discussed in the Section 4.

\section{Please Insert Table 1.}

\subsection{Phase 2: quantitative method}

\subsubsection{Measurements and questionnaire design}

The questionnaire contained four major sections. The measurement scales of each construct were borrowed from previous studies with relevant research contexts, and then modified to fit the current study. In particular, the first section asked participants to indicate their perception on the attributes of the authenticity of traditional branded restaurants. The measurement items of the attributes of the traditional branded restaurant authenticity were derived from previous studies and the interviews (Fritz, Schoenmueller, \& Bruhn, 2017; Jang et al., 2012; Liu et al., 2018). Specifically, the measurement scales of 'food authenticity' and 'environment authenticity' were borrowed from the studies by Jang et al. (2012) and Liu et al. (2018), and the scales of 'nostalgia' were borrowed from the study by Fritz et al. (2017). As for the other attributes include 'historical and cultural value' and 'brand value' that have no available measurement scales, the measurement items were derived directly from the interviews.

The second section asked respondents to rate their perceived quality of food, environment, and service at traditional branded restaurants. 15 items were derived from previous studies (Jang \& Namkung, 2009; Jang et al., 2012; Liu et al., 2018), which have generated measurement items for food quality, service quality, and atmospherics concerning consumers' restaurant dining experience. In the third part, 
participants were asked to suggest their perceived value of the dining experience examining assessing the value of the food, dining environment, and service for the money paid. In particular, five items were adapted from previous studies by Jang et al. (2012) and Liu et al. (2018).

Next, the fourth section examined the behavioural intentions of the participants to the restaurant. A three-item scale was developed from previous research on restaurants (Jang \& Namkung, 2009; Jang et al. 2012) assessing consumers' intentions in term of revisit, positive word of mouth, and willingness to recommend. All the items used in the first three parts were measured using 7-point Likert-type scales ranging from strongly disagree $=1$ to strongly agree $=5$. The last section examined the demographic profiles of respondents including gender, age, and educational level.

\subsubsection{Data collection}

The questionnaire survey was conducted at one of the most well-known traditional branded restaurants-Fuchun teahouse in Yangzhou spanning two weeks from $2^{\text {nd }}$ December to $16^{\text {th }}$ December in 2018. The questionnaire was piloted before use and updated with a few changes in wording. Fuchun teahouse was established in 1885, recognized as the most historical traditional branded restaurants in Yangzhou (Yan \& Zhang, 2017). It was widely acknowledged as the representative restaurant offering the most authentic Huaiyang cuisine in Yangzhou (Li et al., 2019). Its dim sum making skills were dated back to early 20s, and have been noted as a national intangible cultural heritage (Yan \& Zhang, 2017). On this basis, Fuchun teahouse was selected for the main data collection.

A number of research assistants were recruited and trained to conduct the questionnaire at the exit area of the restaurant using an interviewer-completed approach. Research assistants were asked to approach the guests who walkout out of the restaurant using the next-to-pass non-probability sampling technique (Tourism and Recreation Research Unit, 1983). A local souvenir along with a brief introduction of 
the project was provided to the approached respondents to examine their willingness to participate. If the approached person showed willingness to continue the questionnaire interview, screening question was applied by the interviewers to check whether the approached person have just finished dining at the restaurant. In total 435 respondents agreed to participate the survey, and 418 questionnaires were valid and useable for data analysis.

\subsubsection{Data analysis}

SPSS 22.0 was initially employed for descriptive analysis of respondents' demographic profiles, and reliability tests of measurement scales. Then, exploratory factor analysis (EFA) was carried out to examine the dimensionality of the authenticity of traditional branded restaurants. Next, in order to check whether the measurement items reflected the hypothesized latent constructs, confirmatory factor analysis (CFA) was performed. Lastly, once the reliability and validity of the measurement model were satisfied, structural equation modelling (SEM) was applied to test the proposed hypothesis using the software application of AMOS 22.0.

\section{RESULTS}

\subsection{Phase 1: qualitative results}

\subsubsection{Profile of interviewees}

Due to the use of purposive sampling to deliberately select interviewees from different subgroups, of the 68 consumers interviewed who have dined at Yangzhou traditional branded restaurants, half were interviewed from Fuchun teahouse, and half were from Gong hechun teahouse. In terms of the gender, 35 of the participants were female and 33 were male, which is almost evenly distributed. As for the age group, 15 (22\%) interviewees were between 18 and 25 years old, 33 (48.5\%) interviewees were aged between 26 to 45, while $20(29.5 \%)$ interviewees were above the age of 46 . Interviewees profiles are provided in the Appendix 1.

\subsubsection{Results}


With the review of relevant literature on the attributes and influential factors of an authentic dining experience, the analysis of interviews results generated the following items and categories as shown in Table 1 relating to consumers' perceived authenticity of traditional branded restaurants. In particular, the five major categories that got the highest weight from the qualitative interviews summarizing the thematic results were "Food authenticity(155 text units, 33\%)," "Historical and cultural value(101 text units, 22\%)," "Brand value(88 text units, 19\%)," "Environment authenticity(79 text units, 17\%)," and "Nostalgia(41 text units, 9\%)". Apart from the two commonly acknowledged factors 'Environment authenticity' and 'Food authenticity' from previous studies (Jang et al., 2012; Liu et al., 2018), three additional factors include 'Historical and cultural value', 'Brand value' and 'Nostalgia' were highlighted from the interview findings contributing to consumers' perception of authenticity of traditional branded restaurants.

In consistence with previous research, interviewees felt that food is a significant factor that received the highest weight influencing the authenticity of their dining experience (Jang et al., 2012; Kim et al., 2017). Based on the interview results, taste (49 text units), menu (32 text units), ingredients (29 text units), presentation (25 text units), and cooking methods (20 text units) were all relevant items contributing to consumers' perceptions of food (Lin et al., 2017). Specifically, the importance of food as an influential factor to consumers' perceived authenticity is evidenced in two interviewees' statements below:

"The most important factor that attracts me as a tourist to the traditional branded restaurant is definitely the food! As a traditional restaurant that has been opening for such a long time, I just have confidence in the quality of food." (Female, 45, Self-employed, Gong hechun)

"The prawn wonton soup tastes so yummy, the ingredients are so fresh! The crab soup bun is a local specialty that everyone cannot miss. The presentation of the bun 
is innovative and fun. I had never used a straw to eat with the bun. It's expensive but definitely worth the price. The food at this old restaurant just offers me the most authentic local experience." (Female, 25, Employee at enterprise, Fuchun)

Next, "Historical and cultural value" received the second highest weight (101 text units, 22\%). In particular, interviewees emphasized the local culture (33 text units) and history (28 text units) of Yangzhou, as well as the genuine skills of craftsmen(23 text units) and cultural heritage(17 text units) as the essential elements contributing to the authenticity of traditional branded restaurants, which is presented in the following statement. This finding is in line with the study by Lego, Wood and Mcfee (2009) that most consumers choose to dine at an ethnic restaurant with the desire of connecting and interacting with a different culture. Consumers would utilize cultural elements and themes to assess the authenticity of an ethnic restaurant (Lu et al., 2015).

"The restaurant has an open kitchen section that we can actually watch the whole process of the chef making the buns. We were just amazed by their speed and skills making the buns. It is so fast, but every bun looked like exactly the same. We heard the recipe is a secret, and the skills were inherited from many years ago. The history and the culture behind the food at this restaurant just made the dining experience so unique and authentic (Female, 30, Housewife, Fuchun).”

Following, the value of the traditional brands (Brand value) has been highlighted as the third highest factor (88 text units, 19\%) that contribute to the authenticity of the restaurant. This finding is supported by Morhart, Malär, Guèvremont and et al. (2015)'s study, in which brand scandals, marketing efforts on a brand's roots and virtue, and brand anthropomorphism were all relevant cues to evaluate a brand's authenticity. Lu et al. (2015) further corroborated the finding through enhancing the relationship between authenticity and brand equity. It is evidenced in the following quote: 
"It is a very well-known restaurant. I knew this restaurant as one of the 'Chinese time-honored brands' before I came to Yangzhou, and I heard they offered the most authentic crab soup bun in Yangzhou. The well-known brands always make me believe in the hygiene and quality of their food." (Female, 23, Student, Fuchun).

In addition, the environment authenticity of the restaurant has been highlighted as a critical factor by interviewees affecting consumers' perceived authenticity. It is corroborated by many researchers that dining environment has become a significant attribute for consumers to consider when evaluating the authenticity of a restaurant (Jang et al., 2012; Lu et al., 2015). In particular, the interior and exterior design, decorations, music, and employees' uniforms have been highlighted as stimulus associated with the culture in order to create an authentic dining environment (Liu et al., 2018; Lu et al., 2015). The following quotes are presented as evidences:

"The restaurant is built in the traditional Chinese style, located and hidden in a beautiful Yangzhou style garden. When we walked in the restaurant, we were amazed by the traditional decorations and table setting, as well as the exquisite tableware. The ambience of the restaurant and the background music just made us feel so relaxed, and feel like travelling back to the old time. The authentic, traditional feeling was exactly what I have been looking for from the start of this trip.” (Female, 68, Retired, Fuchun)

"Although many waitresses are all in their 40s or 50s, they are extremely friendly and their service are so quick and efficient. Their traditional costumes and service style just match the traditional branded restaurant." (Female,40, Government organizations, Gong hechun).

Last but not the least, in line with previous research (Fritz et al., 2017; Meng,Cai, Day, \& et al., 2019), interviewees noted the impact of the nostalgia feeling in influencing their authenticity perceptions of traditional branded restaurant as evidenced below. 
"As a local, I had been dining at this restaurant for breakfast almost my entire childhood. Although the price of the noodle soup has increased a lot now, the taste still stays the same. More importantly, it represents my most beautiful childhood memory with the family and the city. Now I worked in another city and lived there. However, every time when I came back, this is the place I must visit because it offers the most authentic Yangzhou style noodle." (Male,49, Doctor, Gong hechun).

Nostalgia is one of the variables influencing brand authenticity (Fritz et al., 2017). According to Meng et al. (2019), nostalgia can cause tourists to evaluate perceived authenticity, while perceived authenticity can also arouse tourists' nostalgic feelings and memories about their past experiences. Kessous (2015) noted the cultural dimension of brands as nostalgic, and defined that nostalgic brands were popular in the past and are still popular now. Based on their definition, Chinese traditional branded restaurants can be considered as nostalgic brands. Nostalgic food brands that have lived on through the years are linked to a sense of authenticity, and preferred by the consumers (Kessous, 2015). Peterson (2005) further highlighted that brands are viewed more authentic with the involvement of "former" values. Consequently, nostalgia, identified as a variable influencing authenticity, can become a marketing tool for brands, offering authenticity and quality (Fritz et al., 2017).

\subsection{Phase 2: quantitative results}

\subsubsection{Profile of respondents}

According to the demographic information of the respondents, there are 273 domestic tourists and 145 local consumers. The sample comprised a slightly higher distribution of females $(59.1 \%)$ than males $(40.9 \%)$. It might due to the fact that females are more likely to respond to food-related surveys (Robinson \& Getz, 2014). Around half of the respondents were between the ages of 18 and 35 years old, and it's surprising to notice $23.9 \%$ of the respondents were over 56 years old. This may be explained by the fact the senior consumers are more likely to be attracted by traditional branded 
restaurants than new, fashionable restaurants (Ma et al., 2017). In terms of education level, the sample is well educated that $84.9 \%$ of respondents had at least a college degree. It is likely to be affected by the recent expansion of higher education in China (Wang, Liu \& Lai, 2012).

\subsubsection{Exploratory factor analysis}

Exploratory factor analysis (EFA) was performed to determine the underlying dimensions affecting the authenticity of traditional branded restaurants. The value of the Kaiser-Meyer-Olkin (KMO) measure was 0.944 and the Bartlett's test of sphericity was significant $(\mathrm{p}<.001)$, indicating the data are suitable for EFA (Hair, Anderson, Tatham, \& Black, 1998). The principal components analysis (PCA) with varimax rotation was performed, generating five factors from 23 retained items after deleting items with factor loadings less than 0.40 . The combined eigenvalues of five extracted factors represented $75.719 \%$ of the total variance. These factors were then labeled based on the attributes they cover (Table 2)—namely, historical and cultural brand value, food authenticity, environment authenticity, historical and cultural value, and nostalgia.

In particular, Factor 1, "Environment authenticity", included five items that accounted for $17.511 \%$ of the variance. The second factor consisted of five items, named "Food authenticity", capturing $16.935 \%$ of the variance. Next, four items were extracted and loaded onto factor 3 termed "Historical and cultural value", taking up $15.213 \%$ of the variance. The fourth factor, named "Nostalgia", involved five items explaining $14.749 \%$ of the variance. The last factor, labeled "Brand value", accounted for $11.679 \%$ of the variance. Factor loadings for all 23 items were over 0.60 , which all exceeded the threshold of 0.50 (Hair et al. 2006). With regards to the reliability of the explored factors, the coefficient values were above the threshold of 0.70 (Nunnally, 1978), suggesting the adequate reliability.

\section{Please Insert Table 2.}




\subsubsection{Confirmatory factor analysis}

The reliability and validity of the measurement model was assessed through performing the confirmatory factor analysis (CFA). Table 3 below presents the CFA analysis results. Firstly, reliability was assessed by the composite reliability (CR). The CRs for all factors were higher than 0.80 , indicating good internal consistency reliability values by exceeding the minimal acceptable threshold of 0.70 (Nunnally 1978). Secondly, the measurement model enjoys satisfactory convergent validity due to the average variance extracted (AVE) values of all factors were above the threshold of 0.50 (Fornell and Larcker 1981). Lastly, Fornell and Larcker's (1981) criterion the measurement model has good discriminant validity because the square root of AVE of each factor was above the inter-construct correlations following Fornell and Larcker's (1981) criterion.

\section{Please Insert Table 3.}

\subsubsection{Results of the structural model}

The structural model was assessed to test proposed hypotheses. The goodness-of-fit statistics $(\chi 2=2248.458, \mathrm{df}=926, \chi 2 / \mathrm{df}=2.428, \mathrm{p}<.000, \mathrm{CFI}=0.930, \mathrm{NFI}=0.887$, $\mathrm{IFI}=0.931, \mathrm{TLI}=0.922, \mathrm{RMSEA}=0.059)$ reveal the proposed model reasonably fits the data (MacCallum, Browne, and Sugawara 1996; Hu and Bentler 1999). The structural results of the proposed model are presented in Table 4 and Fig. 2.

Specifically, results show that consumers' overall perception of authenticity was in significant and positive correlation to perceived value at $\beta=0.863, p<0.01$, supporting Hypothesis 1. The direct relationship between perceived value and behavioural intentions was proved significantly positive at $\beta=0.548, \mathrm{p}<0.01$, Hypothesis 2 is thus supported. Next, consumers' perceived authenticity was found to positively influence behavioural intentions at $\beta=0.946, p<0.01$, accepting Hypothesis 3. In addition, the results note perceived authenticity positively influenced 
food quality $(\beta=0.910, \mathrm{p}<0.01)$, environment quality $(\beta=0.881, \mathrm{p}<0.01)$, and service quality $(\beta=0.829, \mathrm{p}<0.01)$. Therefore, the direct correlation between perceived authenticity and perceived quality was confirmed, Hypothesis 4 was accepted. Moreover, regarding the relationships between consumers' perceived quality and perceived value, service quality as a factor was found to positively influence perceived value $(\beta=0.297, \mathrm{p}<0.01)$, partially supporting Hypothesis 5 . However, the other two factors - food quality $(\beta=-.157, \mathrm{p}>0.1)$ and environment quality $(\beta=-.114, p>0.1)$ were not in positive correlation with perceived value, Hypothesis 5 was thus rejected. Finally, the results reveal that consumers' perceived quality of food, environment, and service do not positively influence their behavioural intentions, leading to the rejection of Hypothesis 6.

It is worthy noted that in addition to the proposed hypothesis, the importance of different factors contributing to the perceived authenticity of traditional branded restaurants was revealed. According to Figure 2, among the five factors, historical and cultural value, with a coefficient of 0.886 , is the factor that most influences consumers' perceived authenticity of the dining experience at traditional branded restaurants The other factors followed in order were brand value (0.798), nostalgia (0.786), environment authenticity (0.785), and food authenticity (0.767).

\section{Please Insert Table 4.}

Please Insert Figure 2.

\section{DISUCSSIONS}

This study attempted to assess the role of consumers' perceived authenticity at Chinese traditional branded restaurants through testing the relationships among perceived authenticity, perceived quality of food, service and environment, perceived value, and behavioural intentions. Firstly, the results show that consumers' perceived overall authenticity was in positive association with perceived value, as well as consumers' behavioural intentions. This finding was in line with several studies (Jang 
et al. 2012; Liu and Jang 2009; Liu et al. 2018; Muskat et al. 2019) that have acknowledged the positive role of perceived authenticity on perceived value, and consumers' behavioural intentions in the restaurant context.

Secondly, in order to further assess factors that influence consumers' perceived overall authenticity at Chinese traditional branded restaurants, this study conducted a two-stage research process. In particular, five factors were determined consisting of perceived overall authenticity, which include historical and cultural value, brand value, nostalgia, environment authenticity, and food authenticity. Those five factors were all significant explaining perceived overall authenticity with historical and cultural value recognised as the most influential antecedent, followed by brand value, nostalgia, environment authenticity, and food authenticity. However, this result seems to disagree with two previous studies (Jang et al., 2012; Liu et al., 2018). In particular, it shows contrast to the study by Liu et al. (2018) in the context of a mainstream ethnic restaurant, which revealed food authenticity and environment authenticity comprising overall authenticity, and only environment authenticity is a significant predictor.

The contrasts between the current study and those two studies might be explained by their different research contexts. This study was set in traditional branded restaurants in China with more than 100 years history, which were well recognized for its rich historical and cultural values, as well as brand values. Consequently, in the current research context, not only food and environment could contribute to an authentic dining experience, but also the historical cultural values and brand values of the restaurant, and people' nostalgia feelings could increase consumers' perceived authenticity. Additionally, according to Liu et al. (2018) and Wang and Mattila (2015), the more people are familiar with the culture, the more they will value the authenticity of the restaurants. This study focused on domestic Chinese consumers, despite the factor that the consumers from other cities might not be very familiar with the local culture, they still possess a certain level of Chinese cultural knowledge, which is likely to affect the contrasts with the studies by Jang et al. (2012) and Liu et al. 
(2018).

Thirdly, the results revealed a significant positive relationship between perceived authenticity and perceived quality. This finding was in line with several studies (Akhoondnejad, 2016; Lu et al., 2015; Robinson \& Clifford, 2012) that have acknowledged the direct and significant impacts of consumers' perceived authenticity on perceived quality. Therefore, consumers' perceived authenticity of the traditional branded restaurants predicts their perceived quality.

Fourthly, when this study confirmed that service quality was a significant predictor of consumer perceived value, it is surprising to note that the quality of food and restaurant environment were not in significant correlation to consumer perceived value. These findings contradict with a number of previous studies. In particular, in Ryu et al. (2012)'s study on a Chinese restaurant in the US, food quality was shown in positive association with perceived value while the quality of environment and the quality of service do not significantly influence consumer perceive value. Furthermore, in Jang et al. (2012)'s study on a Korean restaurant, service quality and food quality positively were critical factors influencing perceive value, while quality of the environment was found not as a significant predictor. It is inferred that these conflicts are also induced by the differences in research contexts. Based on the analysis, it is noted that consumers are paying more attention to the quality of service at Chinese traditional branded restaurants.

Lastly, according to the results, no positive direct relationship was shown between consumers' perceived food quality, environment quality, and service quality with their behavioural intentions, respectively. The results seem to disagree with a previous study by Muskat et al. (2019), which confirmed consumers' perceived food quality, service quality, and environment quality of their dining experience were direct and significant predictors of their behavioural intentions. According to Bujisic, Hutchinson and Parsa (2014), the relationship between service quality and 
behavioural intentions depends on the restaurant contexts. Therefore, the contrast might be explained by different restaurant contexts and customer segments.

\section{CONCLUSIONS AND IMPLICATIONS}

This study employed a structural model to examine the role of authenticity at Chinese traditional branded restaurants from the consumers' perspectives, and confirmed its impacts on consumers' perceived value, as well as consumers' behavior intentions. With the utilization of a mixed research approach, this study also confirmed five factors that influence consumers' perceived authenticity of the dining experience at Chinese traditional branded restaurants. In order to have the role of authenticity more accurately assessed, quality of food, service, and restaurant environment were all considered as stimuli in the structural model that might influence consumers' perceived value and behavioural intentions, while the results only supported the positive impacts of service quality on perceived value. Based on above, the analysis of the structural model, as well as the specific influential factors is supposed to provide suggestions to restaurant managers and operators on how to effectively sustain and construct the authenticity of traditional branded restaurants. Both theoretical and practical implications are listed below.

\subsection{Theoretical implications}

This study makes theoretical contributions to the existing research.

(1) Previous literature has mainly focused on investigating consumers' perceived authenticity of ethnic restaurants in a different country, such as Korean restaurant in the US (Jang et al., 2012), Italian restaurant in the US (Liu et al., 2018), and Chinese restaurant in the US (Liu \& Jang, 2009). As one of the first studies investigating authenticity in Chinese traditional branded restaurants, this study extends the research on restaurant authenticity to more varied contexts.

(2) Despite the increasing research attention focusing on examining consumers' authenticity perceptions at restaurants, little attention has been given to investigate the 
specific influential factors. This study enhances the understanding of consumers' perceived authenticity through examining the specific influential factors at Chinese traditional branded restaurants. In particular, in addition to the two commonly identified factors environment authenticity and food authenticity, this study confirmed three additional factors that influences consumers' perception of restaurant authenticity including historical and cultural value, brand value and nostalgia.

(3) This study contributes to a more accurate assessment of the impacts of authenticity perceptions on perceived value with the consideration of the potential impacts of perceived quality. Results indicate that service quality is also a significant predictor of consumers' perceived value in addition to the impacts of their authenticity perceptions. (4) Methodologically, the study makes a significant contribution to the extant literature on consumers' perceptions of restaurant authenticity by employing a mixed-method research design. In particular, the interview approach was used to assess the specific factors influencing consumers' perceived authenticity of traditional branded restaurants, while the survey approach was effectively used in validating all influential factors, as well as assessing the relationships among the theoretical model. This is more likely to result in a study more comprehensive in its scope.

\subsection{Practical implications}

This study also provides a number of practical implications and contributions.

(1) In addition to the positive and direct relationship between consumers' perceived authenticity and behavioural intentions, this study also indicate consumers' perceived service quality of traditional branded restaurants was a significant predictor of their perceived value, which in turn positively influenced their future behavioural intentions. Thus, it is crucial for the operators and managers of traditional branded restaurants in China to devote enough time and effort in creating an authentic dining experience for consumers, as well as to pay attention to every aspect of their service delivery process (Lu et al., 2015). 
(2) The direct and significant impacts of consumers' perceived authenticity on perceived quality further enhanced the implication that restaurant managers and operators should strive to provide a more authentic dining experience. In particular, in terms of consumers' authenticity perceptions of their dining experience at traditional branded restaurants, the results suggest that historical and cultural value of the restaurant was the most significant factor influencing consumers to perceive the dining experience as authentic. Consequently, restaurant managers and operators should initially invest more efforts on presenting the history and culture of the restaurant to the consumers. Specifically, restaurant operators are suggested to offer storytelling about the culture and history of the cuisine and restaurant, as well as acknowledge the value of traditional dim sum making skills and techniques as intangible cultural heritage (Liu et al., 2018; Lin et al., 2017).

(3) In addition to the history and culture of the restaurant, brand value, nostalgia, environment authenticity, and food authenticity were identified as other elements influencing consumers to perceive the dining experience as authentic. Therefore, restaurant managers and operators should also invest time and efforts to those critical components of an authentic dining experience. Firstly, traditional branded restaurants need to protect and emphasize the brand value. According to $\mathrm{Lu}$ et al. (2015), providing effective cues such as regularly communicating consumers involving a logo and a name reflecting the restaurant authenticity through a variety of marketing channels could assist in increasing consumers' brand awareness, and forming brand equity. Secondly, traditional branded restaurants should arouse consumers' nostalgia to appeal to customers. Traditional branded restaurants can organize and promote some activities and events that combines cultures and creative ideas to help consumers seek memories of 'good old times' (Meng et al., 2019). Last but not the least, it is vital for restaurants to pay attention to the authenticity of environment attributes and food attributes (Jang et al. 2012). In particular, restaurants should provide consumers with authentic food taste, ingredients, cooking presentation, and menu choices, as well as authentic atmosphere, interior and exterior design, 
decorations, and background music that reflect the local culture (Liu et al., 2018; Lin et al., 2017; Ryu et al., 2012).

\section{LIMITATIONS AND FUTURE RESEARCH}

In spite of the contributions this study provides, there are several limitations that need to be surmounted in future research. Firstly, additional factors in particular socio-demographics could have potential influences on consumers' perceptions of authenticity as well as their dining experiences. Future studies should consider assessing the potential impacts of these variables for more complete analysis. Secondly, the data of current study was collected from 418 Chinese consumers, which limits the generalisability of the model to populations and restaurants in other countries. Future research could assess the model with a larger sample of consumers from different countries, or with another traditional branded restaurant in another country to further assess the generalisability of the study findings. Thirdly, future research may expand this study by examining the role of authenticity at other branded restaurants in China, and to assess the specific factors that influence consumers' perceived authenticity of the dining experience. It will be interesting to check the comparisons between traditional branded restaurants and other branded restaurants.

\section{References}

Akhoondnejad, A. (2016). Tourist loyalty to a local cultural event: The case of Turkmen handicrafts festival. Tourism Management. 52, 468-477.

Alexander, N. (2009). Brand authentication: Creating and maintaining brand auras. European Journal of Marketing, 43(3/4), 551-562. doi:10.1108/03090560910935578

Atwal, G., \& Williams, A. (2012). Is this Shangri-La? The case for authenticity in the Chinese andIndian hospitality industry. Journal of Brand Management, 19(5), 405-413. doi:10.1057/

bm. 2011.48

Atinc, G., Simmering, M.J. \& Kroll, M.J. (2011). Control variable use and reporting in macro and micromanagement research. Organizational Research Methods, 15(1), 
Braun, V., \& Clarke, V. (2006). Using thematic analysis in psychology. Qualitative Research in Psychology, 3,77-101

Beer, S. (2008). Authenticity and food experience - Commercial and academic perspectives. Journal of Foodservice, 19, 153-163. doi:10.1111/j.1745-4506.2008.00096.x

Bruhn, M., Schoenmüller, V., Schäfer, D., \& Heinrich, D. (2012). Brand Authenticity: Towards a Deeper Understanding of Its Conceptualization and Measurement. Advances in Consumer Research. 40, 567-576.

Budruk, M., White, D. D., Wodrich, J. A., \& van Riper, C. J. (2008). Connecting visitors to people and place: visitors' perceptions of authenticity at Canyon de Chelly National Monument, Arizona. Journal of Heritage Tourism, 3,185-202.

Bujisic M, Hutchinson J, \& Parsa, H.G. (2014). The effects of restaurant quality attributes on customer behavioral intentions. International Journal of Contemporary Hospitality Management, 26(8), 1270-1291.

Chang, K.C. (1977). Food in Chinese culture. New Haven (CT): Yale University Press.

Chen, P. O. \& Hu, H. H. (2010). How determinant attributes of service quality influence customer-perceived value: An empirical investigation of the Australian coffee outlet industry. International Journal of Contemporary Hospitality Management, 22(4), 535-551.

Chen, Q. \& Huang, R. (2016). Understanding the importance of food tourism to Chongqing, China. Journal of Vacation Marketing, 22(1), 42-54.

Chen, Q. \& Huang, R. (2018). Local food in China: A viable destination attraction. British Food Journal, 120(1), 146-157.

Chen, Q. \& Huang, R. (2019).Understanding the role of local food in sustaining Chinese destinations, Current Issues in Tourism, 22(5), 544-560.

Cohen, E. (1988). Authenticity and commoditization in tourism. Annals of Tourism Research, 15(3), 371-386. doi:10.1016/0160-7383(88)90028-X

Creswell, J. W. (2007). Qualitative inquiry and research design: Choosing among five approaches (2nd ed.). Thousand Oaks, CA: Sage. 
Creswell, J. W., \& Clark, V. L. (2011). Designing and Conducting Mixed Methods Research (2nd ed.). Thousand Oaks, CA Sage.

Cappannelli, G. \& Cappannelli, S.C. (2004) Authenticity: Simple Strategies for Greater Meaning and Purpose at Work and at Home. Emmis Books.

DiPietro, R.B. \& Levitt, J. (2019). Restaurant Authenticity: Factors That Influence Perception, Satisfaction and Return Intentions at Regional American-Style Restaurants. International Journal of Hospitality \& Tourism Administration, 20(1), $101-127$

Domenge, R. \& Arciniega, L.M. (2015). Development of a short questionnaire for measuring service quality perceptions. Decision, 42(1), 11-17.

Dayour, F., Park, S., \& Kimbu, A. (2019). Backpackers' perceived risks towards smartphone usage and risk reduction strategies: a mixed methods study. 72, 52-68.

Eggert, A. \& Ulaga,W. (2002). Customer perceived value: A substitute for satisfaction in business markets? Journal of Business \& Industrial Marketing, 17, 107-118. doi:10.1108/08858620210419754

Evanschitzky, H., Iyer, G.R., Plassmann, H., Niessing, J., \& Meffert, H. (2006). The relative strength of affective commitment in securing loyalty in service relationships. Journal of Business Research 59, 1207-1213.

Fine, G.A. (2003). Crafting Authenticity: The Validation of Identity in Self-Taught Art, Theory and Society, 32, 153- 180.

Fornell, C., \& Larcker, D. F. (1981). Evaluating structural equation models with unobservable variables and measurement error. Journal of Marketing Research, 18(2), 161-188. doi:10.2307/3151312

Fritz,K., Schoenmueller, V. \& Bruhn, M. (2017). Authenticity in branding-exploring antecedents and consequences of brand authenticity. European Journal of Marketing. 51(2). 324-348.

Fu, Y., Liu, X.M., Wang, Y.Q., \& Chao, R.F.(2018). How experiential consumption moderates the effects of souvenir authenticity on behavioral intention through perceived value. Tourism Management, 69, 356-367.

Gilmore, J.H. \& Pine, B.J. (2007). Authenticity: What Consumers Really Want, Harvard Business School Press, Boston, MA

Glaser, B. G., \& Strauss, A. (1967). The discovery of grounded theory: Strategies for 
qualitative research. Chicago, IL: Aldine.

Grayson, K., \& Martinec, R. (2004). Consumer perceptions of iconicity and indexicality and their influence on assessments of authentic market offerings. Journal of Consumer Research, 31(2), 296-312.

Ha, J. \& Jang, S. (2010). Perceived values, satisfaction, and behavioral intentions: the role of familiarity in Korean restaurants. International Journal of Hospitality Management, 29(1), 2-13.

Hair Jr, J. F., Black, W. C., Babin, B. J., Anderson, R. E., \& Tatham, R. L. (2006). Multi-variate data analysis. Upper Saddle River, NJ: Prentice-Hall

Han, H \& Hyun, S.S. (2017). Impact of hotel-restaurant image and quality of physical-environment, service, and food on satisfaction and intention. International Journal of Hospitality Management, 63, 82-92.

Han, H. \& Ryu, K. (2009). The roles of the physical environment, price perception, and customer satisfaction in determining customer loyalty in the restaurant industry. Journal of Hospitality \& Tourism Research, 33(4), 487-510.

Hewlett, D. \& Brown, L. (2018). Planning for tranquil spaces in rural destinations through mixed methods research. 67, 237-247

Holt, D.B. (2002). Why Do Brands Cause Trouble? A Dialectical Theory of Consumer Culture and Branding. Journal of Consumer Research, 26, 70-90.

Hou, B., Tao, R., \& Chen, Q. (2016). Perception and evaluation of urban food culture landscape image based on analysis of travels notes on the Internet: A case study of Yangzhou. Journal of Researches on Dietetic Science and Culture. 33(04),20-25.

Jamal, T. \& Hill, S (2004). Developing a Framework for Indicators of Authenticity: The Place and Space of Cultural and Heritage Tourism. Asia Pacific Journal of Tourism Research, 9 (4), 353-371

Jang, S., \& Namkung, Y. (2009). Perceived quality, emotions, and behavioral intentions: application of an extended Mehrabian-Russell model to restaurants. Journal of Business Research, 62, 451-460

Jang, S., Ha, J., \& Park, K. (2012). Effects of ethnic authenticity: Investigating Korean restaurant customers in the U.S. International Journal of Hospitality Management, 31, 990-1003. doi:10.1016/j.ijhm.2011.12.003

Kessous,A. (2015). Nostalgia and brands: a sweet rather than a bitter cultural 
evocation of the past, Journal of Marketing Management, 31(17-18), 1899-1923

Kovács, B., Carroll, G.R. \& Lehman, D.W. (2014).Authenticity and consumer value ratings: empirical tests from the restaurant domain. Organization Science, 25(2), 458-478.

Kim,J.H., Youn,H., \& Rao,Y. (2017). Customer responses to food-related attributes in ethnic restaurants. International Journal of Hospitality Management, 61, 129-139.

Kim, H. \& Jamal, T. (2007). Touristic quest for existential authenticity. Annals of Tourism Research, 34 (1), 181-201

Kim, H. \& Boon, M. A. (2016). Authenticity-Do tourist perceptions of winery experiences

affect behavioral intentions? International Journal of Contemporary Hospitality Management. 28(4), 839-85.

Kotler, P., 1973. Atmospherics as a marketing tool. Journal of Retailing, 49 (4), $48-64$.

Lai, I.K. (2015). The roles of value, satisfaction, and commitment in the effect of service quality on customer loyalty in Hong Kong-style tea restaurants. Cornell Hospitality Quarterly, 56(1), 118-138.

Lego, C., Wood, N., \& Mcfee, S.A. (2002). Thirst for The Real Thing in Themed Retail Environments: Consuming Authenticity in Irish Pubs. Journal of Foodservice Business Research, 5(2), 61-74.

Lee, J. \& Whaley, J.E. (2018). Determinants of dining satisfaction. Journal of Hospitality Marketing and Management. 1-28. 351-378

Li, M., Hou, B., \& Xu, Y.R. (2019). The ingenuity of Huaiyang dietetic culture and its tourism value under the background of roaming. Journal of Researches on Dietetic Science and Culture. 36(01), 27-32.

Lin, C. H., \& Wang, W. C. (2012). Effects of authenticity perception, hedonics, and perceived value on ceramic souvenir-repurchasing intention. Journal of Travel \& Tourism Marketing, 29(8), 779-795

Lin, S.P., Chan, Y.H., \& Tsai, M.C. (2009). A transformation function corresponding to IPA and gap analysis. Total Quality Management \& Business Excellence, 20, 829-846

Lin,P.M.C., Ren,L.P., \& Chen,C.(2017). Customers' Perception of the Authenticity of 
a Cantonese Restaurant. Journal of China Tourism Research, 13(2),211-230,doi: $10.1080 / 19388160.2017 .1359721$

Liu, P. \& Tse, E.C. (2018). Exploring factors on customers' restaurant choice: An analysis of restaurant attributes. British Food Journal. 120, 2289-2303.

Lovelock, C. H. (2000). Service marketing (4th ed.). Upper Saddle River, NJ: Prentice Hall International.

Liu, Y. \& Jang, S. (2009). Perceptions of Chinese restaurants in the US: what affects customer satisfaction and behavioral intentions. International Journal of Hospitality Management, 28(3), 338-348

Liu, H.B., Li, H.Y., DiPietro,R.B., \& Levitt,J.A. (2018). The role of authenticity in mainstream ethnic restaurants: Evidence from an independent full-service Italian restaurant, International Journal of Contemporary Hospitality Management,30(2), 1035-1053.

Lu, A.C.C., Gursoy, D., \& Lu, C.Y.R. (2015). Authenticity perceptions, brand equity and brand choice intention: The case of ethnic restaurants. International Journal of Hospitality Management, 50, 36-45.

Lu, S., \& Fine, G.A. (1995). The presentation of ethnic authenticity: Chinese food as a social accomplishment. The Sociological Quarterly, 36, 535-553

Ma, X. Y., Wei, W.W., \& Bai, Y. (2017). Types and Mechanism of Perceived Brand Authenticity Clues in Old Brand Restaurants - Social Network Analysis on Chinese Time-honored Restaurants. East China Economic Management, 31(8), 176-184. [In Chinese]

MacCannell, D. (1973). Staged authenticity: Arrangements of social space in tourist settings. American Journal of Sociology, 79, 589-603.

Meng, Z.H., Cai, L.P., Day, J., Tang, C.H., Lu, Y. \& Zhang, H.M. (2019). Authenticity and nostalgia - subjective well-being of Chinese rural-urban migrants. Journal of Heritage Tourism, DOI: 10.1080/1743873X.2019.1567739

Molz, J. G. (2007). Eating difference. Space and Culture, 10(1), 77-93.

Morhart, F., Malär, L., Guèvremont, A., Girardin, F., \& Grohmann, B. (2015). Brand authenticity: An integrative framework and measurement scale. Journal of Consumer Psychology, 25(2), 200-218

Muskat, B., Hortnagl, T., Prayag, G., \&Wagner, S. (2019). Perceived quality, 
authenticity,

and price in tourists' dining experiences: Testing competing models of satisfaction and

behavioral intentions. Journal of Vacation Marketing,1-19. DOI: $10.1177 / 1356766718822675$

Nikolich, M.A., Sparks, B.A., 1995. The hospitality service encounter: the role of communication. Journal of Hospitality and Tourism Research, 19 (2), 43-56.

Nunnally, J. C. (1978). Psychometric theory (2nd ed.). New York: McGraw-Hill.

Oum, Y. R. (2005). Authenticity and representation: Cuisines and identities in Korean-American diaspora. Postcolonial Studies: Culture, Politics, Economy, 8(1), 109-125. doi:10.1080/ 13688790500134380

Oh, H. (2000). Diners' Perceptions of Quality, Value and Satisfaction. Cornell Hotel and Restaurant Administration Quarterly, 41 (3), 58-66.

Parasuraman, A., Zeithaml, V.A. and Berry, L.L. (1988), SERVQUAL: a multiple-item scale for measuring consumer perceptions of service quality. Journal of Retailing, 64(1), 12-37.

Peterson, R. A. (2005). In search of authenticity. Journal of Management Studies, 42(5), 1083- 1098. doi:10.1111/j.1467-6486.2005.00533.x

Ramkissoon, H. \& Uysal, M. (2011). The effects of perceived authenticity, information search behaviour, motivation and destination imagery on cultural behavioural intentions of tourists. Current Issues in Tourism, 14(6), 537-562.

Robinson, R.N.S. and Clifford, C. (2012). Authenticity and festival foodservice experiences. Annals of Tourism Research, 39(2), 571-600.

Ryu, K.S. and Jang, S.C.S. (2007). The effect of environmental perceptions on behavioral intentions through emotions: the case of upscale restaurants. Journal of Hospitality \& Tourism Research, 31(1), 56-72.

Ryu, K., Han, H. and Jang, S. (2010). Relationships among hedonic and utilitarian values, satisfactionand behavioral intentions in the fast-casual restaurant industry. International Journal of Contemporary Hospitality Management, 22(3), 416-432.

Ryu, K., Han, H. and Kim, T.H. (2008). The relationships among overall quick-casual restaurant image, perceived value, customer satisfaction, and behavioral intentions. International Journal of Hospitality Management, 27(3), 459-46. 
Robinson, R. N. S., \& Clifford, C. (2012). Authenticity and festival foodservice experiences. Annals of Tourism Research, 39(2), 571-600. https://doi.org/10.1016/j. annals.2011.06.007

Sánchez, J., Callarisa, L., Rodríguez, R. M., \& Moliner, M. A. (2006). Perceived value of the purchase of a tourism product. Tourism Management, 27(3), 394-409. doi:10.1016/j.tourman.2004.11.007

Sweeney, J. C., \& Soutar, G. N. (2001). Consumer perceived value: The development of a multiple item scale. Journal of Retailing, 77(2), 203-220. doi:10.1016/S0022-4359(01)000410

Sims, R. (2009). Food, place and authenticity: Local food and the sustainable tourism experience. Journal of Sustainable Tourism, 17(3), 321-336. doi:10.1080/09669580802359293

Teddlie, C., \& Tashakkori, A. (2006). A general typology of research designs featuring mixed methods. Research in the Schools, 13(1), 12-28.

Tourism and Recreation Research Unit. (1983). Recreation site survey manual methods and techniques for conducting visitor surveys. London: E. \& F. N. Spon.

Tsai, C.T., \& Lu, P.H. (2012). Authentic dining experiences in ethnic theme restaurants. International Journal of Hospitality Management,31,304-306. doi:10.1016/j.ijhm.2011.04.010

Ward, L. M., \& Russell, J. A. (1981). The psychological representation of molar physical environments. Journal of Experimental Psychology, 110(2), 121-152.

Wang, D., Liu, D., \& Lai, C. (2012). Expansion of higher education and the employment crisis: Policy innovations in China. On the Horizon, 20, 336-344.

Wang, N. (1999). Rethinking authenticity in tourism experience. Annals of Tourism Research, 26(2), 349-370. doi:10.1016/S0160-7383(98)00103-0

Wang, C.Y. \& Mattila, A.S. (2015). The Impact of Servicescape Cues on Consumer Prepurchase Authenticity Assessment and Patronage Intentions to Ethnic Restaurants. Journal of Hospitality and Tourism Research, 39(3), 346-372.

Wang, C.Z. \& Wang, Y.J. (2014). Evaluation Model of Time-honored Brand Value. Management Review, 26(6), 98-106. [In Chinese]

Wells, V. K., Manika, D., Gregory-Smith, D.,Taheri, B., Mccowlen, C. (2015). Heritage tourism, CSR and the role of employee environmental behaviour. Tourism 
Management, 48, 399-413.

Wood, N.T., \& Munoz, C.L. (2006). 'No rules, just right' or is it? The role of themed restaurants as cultural ambassadors. Tourism and Hospitality Research, 7 (3/4), $242-255$.

Xu, W. \& Feng, L. (2018). Research on Influence Mechanism of Time-honored Brand Authenticity on Intentions of Word-of-mouth. Journal of Central University of Finance and Economic. 1, 93-101. [In Chinese]

Xu, W., Wang, P., Wang, X.X., \& Song, S. G. (2015). Time-honored brand authenticity: its measurement and influence. Chinese Journal of Management, 12(9), 1286-1293. [In Chinese]

Yan, M.J \& Zhang, Q. (2017). Customers' satisfaction degree of time-honored catering brands based on IPA- A case of Fuchun Tea House, Yangzhou. Journal of Researches on Dietetic Science and Culture. 34(01), 45-50.

Zeithaml, V.A. (1988). Consumer perceptions of price, quality, and value: a means-end model and synthesis of evidence. The Journal of Marketing, 52(3), 2-22.

Zeithaml, V.A., Berry, L.L., Parasuraman, A., 1996. The behavioral consequences of service quality. Journal of Marketing 60 (2), 31-46.

Table 1. Categories and items of customer perceptions on authenticity of traditional branded restaurant

\begin{tabular}{|l|l|l|}
\hline $\begin{array}{l}\text { Categories } \\
\text { (Total number } \\
\text { of text units/ } \\
\text { percentage) }\end{array}$ & $\begin{array}{l}\text { Subcategories } \\
\text { (number of text } \\
\text { units) }\end{array}$ & Representative comments \\
\hline $\begin{array}{l}\text { Food } \\
\text { Authenticity } \\
155(33 \%)\end{array}$ & $\begin{array}{l}\text { Taste } \\
49\end{array}$ & $\begin{array}{l}\text { The taste is good and authentic; it doesn't taste as } \\
\text { authentic as ten years ago. }\end{array}$ \\
\hline & Menu/variety & A variety of choices; it offers the most authentic local \\
\hline
\end{tabular}




\begin{tabular}{|c|c|c|}
\hline & 32 & $\begin{array}{l}\text { delicacies; some local specialties that cannot miss: crab } \\
\text { soup bun, steamed dumplings, Yangzhou baozi, prawn } \\
\text { wonton soup, boiled shredded bean curd. }\end{array}$ \\
\hline & $\begin{array}{l}\text { Ingredients } \\
29\end{array}$ & We knew the ingredients are fresh and locally sourced. \\
\hline & $\begin{array}{l}\text { Presentation/ } \\
\text { Look } \\
25\end{array}$ & $\begin{array}{l}\text { The presentation of the bun is innovative and fun; the } \\
\text { presentation of the dish gives us a kind of poetic } \\
\text { feeling just as exactly as what Yangzhou offers us. }\end{array}$ \\
\hline & $\begin{array}{l}\text { Cooking methods } \\
20\end{array}$ & $\begin{array}{l}\text { The food is cooked in the original Huaiyang style, } \\
\text { which are very healthy; the cooking methods in } \\
\text { Yangzhou are very different from our home cooking. }\end{array}$ \\
\hline \multirow[t]{4}{*}{$\begin{array}{l}\text { Historical and } \\
\text { Cultural Value } \\
101(22 \%)\end{array}$} & $\begin{array}{l}\text { Local culture } \\
33\end{array}$ & $\begin{array}{l}\text { It is one of the ways for us to get to know Yangzhou } \\
\text { local culture; Eating at the most traditional restaurant is } \\
\text { experiencing the most authentic Yangzhou culture. }\end{array}$ \\
\hline & $\begin{array}{l}\text { History } \\
28\end{array}$ & $\begin{array}{l}\text { We know it has a history of more than } 100 \text { years; it is } \\
\text { full of historic feelings }\end{array}$ \\
\hline & $\begin{array}{l}\text { Traditional skills \& } \\
\text { techniques } \\
23\end{array}$ & $\begin{array}{l}\text { The delicate Yangzhou dim sum reflects chef's } \\
\text { excellent skills and techniques, which were secretly } \\
\text { passed from one generation to another. }\end{array}$ \\
\hline & $\begin{array}{l}\text { Cultural heritage } \\
17\end{array}$ & $\begin{array}{l}\text { Our local friends told us their dim sum making skills as } \\
\text { one of our national intangible cultural heritages could } \\
\text { date back to more than } 100 \text { years ago. }\end{array}$ \\
\hline \multirow[t]{5}{*}{$\begin{array}{l}\text { Brand Value } \\
88(19 \%)\end{array}$} & $\begin{array}{l}\text { Fame/popularity } \\
37\end{array}$ & $\begin{array}{l}\text { Before we came here, we already knew this is the local } \\
\text { most famous, and popular traditional branded } \\
\text { restaurant. }\end{array}$ \\
\hline & $\begin{array}{l}\text { Brand impacts } \\
16\end{array}$ & $\begin{array}{l}\text { I prefer authentic food at every tourist destination, and } \\
\text { the traditional brand of the restaurant motivates me to } \\
\text { come as my first stop after getting off the train. }\end{array}$ \\
\hline & $\begin{array}{l}\text { Risk free } \\
11\end{array}$ & $\begin{array}{l}\text { In my perception, eating at local traditional branded } \\
\text { restaurant doesn't take high risks because it usually } \\
\text { provides more authentic food than others. }\end{array}$ \\
\hline & $\begin{array}{l}\text { Brand value } \\
16\end{array}$ & $\begin{array}{l}\text { I like trying traditional branded restaurants everywhere } \\
\text { because the all those brands have been at least exiting } \\
\text { for more than } 50 \text { years, and their brand value was } \\
\text { enormous. }\end{array}$ \\
\hline & Brand trust & $\begin{array}{l}\text { Compared to other types of restaurants, we usually tend } \\
\text { to have more faith in the quality of food provided by } \\
\text { traditional branded restaurant. }\end{array}$ \\
\hline \multirow[t]{2}{*}{$\begin{array}{l}\text { Environment } \\
\text { Authenticity } \\
79(17 \%)\end{array}$} & $\begin{array}{l}\text { Interior } \\
\text { Design } \\
23\end{array}$ & $\begin{array}{l}\text { The interior design is traditionally Yangzhou style, } \\
\text { which shows the antique and classic beauty. }\end{array}$ \\
\hline & $\begin{array}{l}\text { Decorations } \\
18\end{array}$ & $\begin{array}{l}\text { On the wall of the restaurants, there are many local } \\
\text { decorations e.g. the well-known poems and paintings }\end{array}$ \\
\hline
\end{tabular}




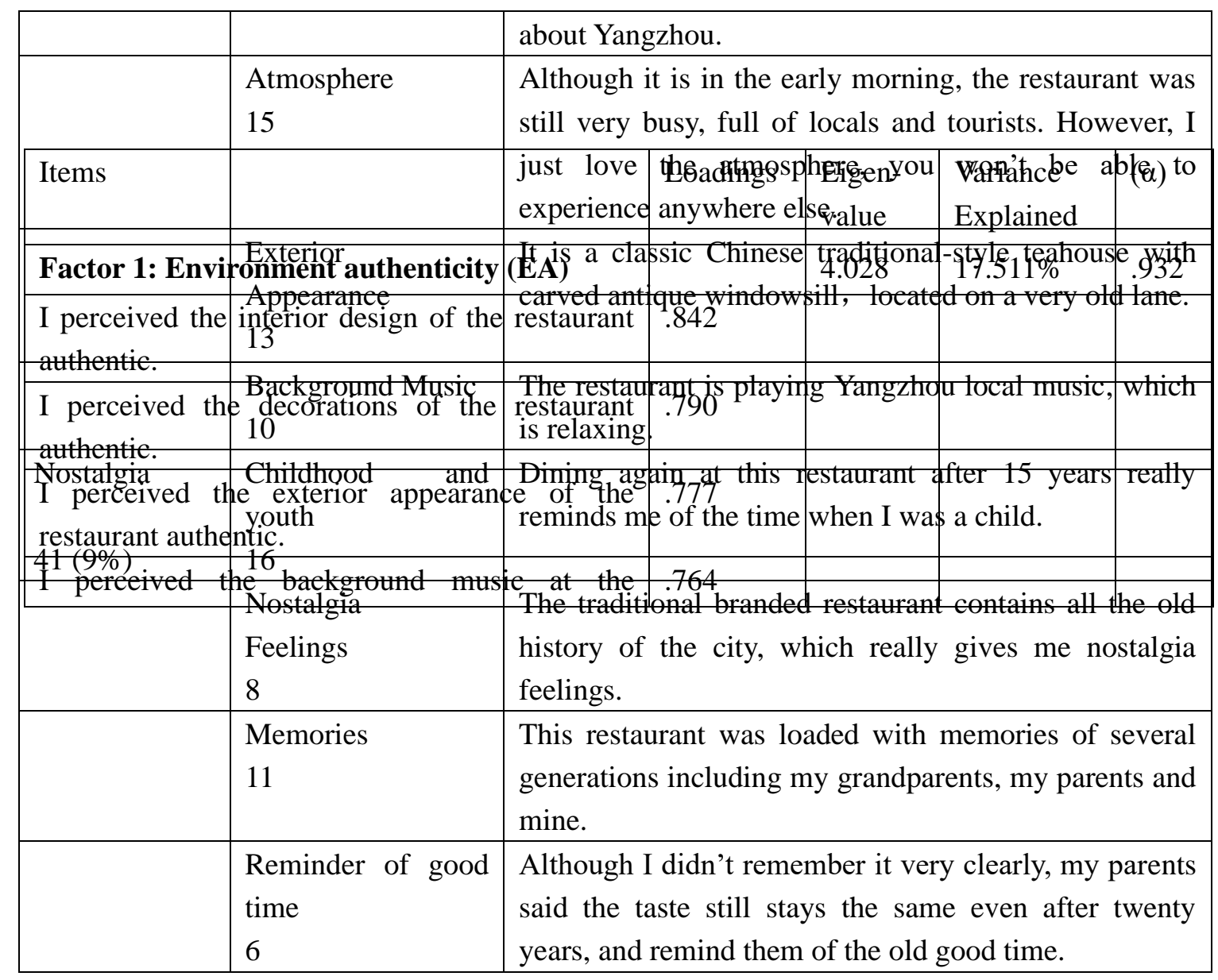

Table 2. Exploratory factor analysis results 


\begin{tabular}{|c|c|c|c|c|}
\hline restaurant authentic. & & & & \\
\hline $\begin{array}{l}\text { I perceived the atmosphere at the restaurant } \\
\text { authentic. }\end{array}$ & .724 & & & \\
\hline Factor 2: Food authenticity (FA) & & 3.895 & $16.935 \%$ & .913 \\
\hline I perceived the ingredients of the food authentic. & .807 & & & \\
\hline $\begin{array}{l}\text { I perceived the menu and choices of dishes } \\
\text { authentic. }\end{array}$ & .798 & & & \\
\hline $\begin{array}{l}\text { I perceived the presentation of the food } \\
\text { authentic. }\end{array}$ & .750 & & & \\
\hline $\begin{array}{l}\text { I perceived the taste of the food good and } \\
\text { authentic. }\end{array}$ & .737 & & & \\
\hline $\begin{array}{l}\text { I perceived the cooking methods of dishes } \\
\text { authentic. }\end{array}$ & .720 & & & \\
\hline Factor 3: Historical and cultural value (HC) & & 3.499 & $15.213 \%$ & .916 \\
\hline $\begin{array}{l}\text { Traditional branded restaurant possesses great } \\
\text { historical and cultural value, and makes people } \\
\text { more involved with the destination. }\end{array}$ & .775 & & & \\
\hline $\begin{array}{l}\text { Traditional branded restaurant reflects great } \\
\text { local tradition and history. }\end{array}$ & .765 & & & \\
\hline $\begin{array}{l}\text { Dining at traditional branded restaurant enables } \\
\text { me to better understand the local culture. }\end{array}$ & .722 & & & \\
\hline $\begin{array}{l}\text { Traditional branded restaurant assists in the } \\
\text { inheritance of traditional techniques and skills. }\end{array}$ & .716 & & & \\
\hline Factor 4: Nostalgia (NOS) & & 3.392 & $14.749 \%$ & .921 \\
\hline $\begin{array}{l}\text { Traditional branded restaurant is a reminder of } \\
\text { the happy time in the past. }\end{array}$ & .842 & & & \\
\hline $\begin{array}{l}\text { Traditional branded restaurant represents the } \\
\text { memory of childhood and youth. }\end{array}$ & .813 & & & \\
\hline $\begin{array}{l}\text { Traditional branded restaurant gave me the } \\
\text { nostalgia feelings }\end{array}$ & .722 & & & \\
\hline $\begin{array}{l}\text { Traditional branded restaurant made me think of } \\
\text { the old memories. }\end{array}$ & .709 & & & \\
\hline Factor 5: Brand value (BV) & & 2.686 & $11.679 \%$ & .818 \\
\hline The brand value of the restaurant is enormous. & .715 & & & \\
\hline $\begin{array}{l}\text { Traditional branded restaurant is very popular } \\
\text { with consumers, and enjoys high-profile brand } \\
\text { value. }\end{array}$ & .707 & & & \\
\hline $\begin{array}{l}\text { The traditional brand of the restaurant makes me } \\
\text { think I am more likely to have the authentic } \\
\text { food. }\end{array}$ & .697 & & & \\
\hline $\begin{array}{l}\text { The brand value of the restaurant is an important } \\
\text { motivating factor for my visit. }\end{array}$ & .545 & & & \\
\hline
\end{tabular}




\begin{tabular}{|l|l|l|l|l|}
\hline $\begin{array}{l}\text { Compared to other restaurants, I have more faith } \\
\text { in the quality of the food provided by restaurants } \\
\text { with traditional brands. }\end{array}$ & & & & \\
\hline
\end{tabular}

Table 3. Confirmatory factor analysis results.

\begin{tabular}{|l|l|l|l|l|}
\hline & Scale Items & Loadings & $\begin{array}{l}\text { Composite } \\
\text { Reliability }\end{array}$ & AVE \\
\hline \multirow{5}{*}{ Perceived Authenticity } & Nostalgia & 0.803 & 0.905 & 0.655 \\
\cline { 2 - 5 } & BrandValue & 0.823 & & \\
\cline { 2 - 5 } & FoodAuthenti & 0.783 & & \\
\cline { 2 - 5 } & HistorandCul & 0.846 & & \\
\cline { 2 - 5 } & EnvirAuthenti & 0.79 & & \\
\hline \multirow{3}{*}{ Brand Value } & BV1 & 0.871 & 0.885 & 0.605 \\
\hline & BV3 & 0.769 & & \\
\hline
\end{tabular}




\begin{tabular}{|c|c|c|c|c|}
\hline & BV2 & 0.868 & & \\
\hline & BV4 & 0.740 & & \\
\hline & BV5 & 0.701 & & \\
\hline \multirow[t]{4}{*}{ Nostalgia } & NOS4 & 0.791 & 0.929 & 0.724 \\
\hline & NOS3 & 0.815 & & \\
\hline & NOS2 & 0.902 & & \\
\hline & NOS1 & 0.908 & & \\
\hline \multirow{4}{*}{$\begin{array}{l}\text { Historical and Cultural } \\
\text { Value }\end{array}$} & $\mathrm{HC} 4$ & 0.832 & & \\
\hline & $\mathrm{HC} 3$ & 0.871 & 0.932 & 0.731 \\
\hline & $\mathrm{HC} 2$ & 0.853 & & \\
\hline & $\mathrm{HC} 1$ & 0.874 & & \\
\hline \multirow[t]{5}{*}{ Food Authenticity } & FA4 & 0.845 & 0.920 & 0.696 \\
\hline & FA3 & 0.852 & & \\
\hline & FA2 & 0.81 & 0.929 & 0.696 \\
\hline & FA1 & 0.833 & & \\
\hline & FA5 & 0.831 & & \\
\hline \multirow{5}{*}{$\begin{array}{l}\text { Environment } \\
\text { Authenticity }\end{array}$} & EA1 & 0.862 & 0.935 & 0.742 \\
\hline & EA2 & 0.872 & & \\
\hline & EA3 & 0.868 & & \\
\hline & EA4 & 0.888 & & \\
\hline & EA5 & 0.814 & & \\
\hline
\end{tabular}

Table 4. Results of structural model and hypotheses testing $(\mathrm{N}=418)$

\begin{tabular}{|l|l|l|}
\hline Hypothesized Relationships & Coefficient & Results \\
\hline H1: Perceived authenticity $\rightarrow$ perceived value & $.863^{* * *}$ & Accepted \\
\hline H2: Perceived value $\rightarrow$ behavioural intentions & $.548^{* * *}$ & Accepted \\
\hline H3: Perceived authenticity $\rightarrow$ behavioural intentions & $.946^{* * *}$ & Accepted \\
\hline H4-1: Perceived authenticity $\rightarrow$ Food quality & $.910^{* * *}$ & Accepted \\
\hline H4-2: Perceived authenticity $\rightarrow$ Environment quality & $.881^{* * *}$ & Accepted \\
\hline H4-3: Perceived authenticity $\rightarrow$ Service quality & $.829 * * *$ & Accepted \\
\hline H5-1: Food quality $\rightarrow$ perceived value & -.157 & Rejected \\
\hline
\end{tabular}




\begin{tabular}{|l|l|l|}
\hline H5-2: Environment quality $\rightarrow$ perceived value & -.114 & Rejected \\
\hline H5-3: Service quality $\rightarrow$ perceived value & $.297^{* * *}$ & Accepted \\
\hline H6-1: Food quality $\rightarrow$ behavioural intentions & -.049 & Rejected \\
\hline H6-2: Environment quality $\rightarrow$ behavioural intentions & -.353 & Rejected \\
\hline H6-3: Service quality $\rightarrow$ behavioural intentions & -.226 & Rejected \\
\hline
\end{tabular}

Appendix 1. Profiles of Interviewees 


\begin{tabular}{|l|l|l|l|l|}
\hline No. & Gender & Age & Occupation & $\begin{array}{l}\text { Interview } \\
\text { location }\end{array}$ \\
\hline 1. & Male & 47 & Enterprises & Fuchun \\
\hline 2. & Female & 45 & Self-employed & Fuchun \\
\hline 3. & Female & 20 & Student & Fuchun \\
\hline 4. & Male & 19 & Student & Fuchun \\
\hline 5. & Female & 24 & Student & Fuchun \\
\hline 6. & Female & 30 & Government organizations & Fuchun \\
\hline 7. & Female & 45 & Housewife & Fuchun \\
\hline 8. & Female & 70 & Retired & Fuchun \\
\hline 9. & Male & 35 & Researcher & Fuchun \\
\hline 10. & Female & 39 & Nurse & Fuchun \\
\hline 11. & Male & 65 & Retired & Fuchun \\
\hline 12. & Male & 40 & Teacher & Fuchun \\
\hline 13. & Female & 58 & Retired & Fuchun \\
\hline 14. & Male & 45 & Enterprises & Fuchun \\
\hline 15. & Male & 20 & Student & Fuchun \\
\hline 16. & Female & 27 & Enterprises & Fuchun \\
\hline 17. & Female & 68 & Retired & Fuchun \\
\hline 18. & Female & 25 & Enterprises & Fuchun \\
\hline 19. & Male & 45 & Enterprises & Fuchun \\
\hline 20. & Male & 40 & Enterprises & Fuchun \\
\hline 21. & Female & 21 & Student & Fuchun \\
\hline 22. & Male & 38 & Government organizations & Fuchun \\
\hline 23. & Female & 42 & Housewife & Fuchun \\
\hline 24. & Male & 57 & Government organizations & Fuchun \\
\hline 25. & Male & 47 & Self-employed & Fuchun \\
\hline 26. & Female & 23 & Student & Fuchun \\
\hline 27. & Male & 30 & Enterprises & Fuchun \\
\hline 28. & Male & 50 & Enterprises & Fuchun \\
\hline 29. & Female & 45 & Housewife & Fuchun \\
\hline 30. & Female & 38 & Teacher & Fuchun \\
\hline 31. & Male & 70 & Retired & Fuchun \\
\hline 32. & Female & 30 & Housewife & Fuchun \\
\hline 33. & Male & 63 & Retired & Fuchun \\
\hline 34. & Male & 22 & Student & Fuchun \\
\hline 35. & Female & 21 & Student & Gong hechun \\
\hline 36. & Male & 37 & Enterprises & \\
\hline 37. & Female & 28 & Enterprises & Gong hechun \\
\hline 38. & Male & 31 & Self-employed \\
\hline 39. & Female & 74 & Retired & \\
\hline 40. & Female & 20 & Student & \\
\hline & & & & Gong \\
\hline
\end{tabular}




\begin{tabular}{|l|l|l|l|l|}
\hline 41. & Female & 52 & Self-employed & Gong hechun \\
\hline 42. & Male & 40 & Enterprises & Gong hechun \\
\hline 43. & Female & 21 & Student & Gong hechun \\
\hline 44. & Female & 24 & Student & Gong hechun \\
\hline 45. & Male & 34 & Government organizations & Gong hechun \\
\hline 46. & Male & 20 & Student & Gong hechun \\
\hline 47. & Female & 40 & Government organizations & Gong hechun \\
\hline 48. & Male & 33 & Enterprises & Gong hechun \\
\hline 49. & Female & 56 & Retired & Gong hechun \\
\hline 50. & Male & 50 & Government organizations & Gong hechun \\
\hline 51. & Female & 57 & Retired & Gong hechun \\
\hline 52. & Male & 49 & Doctor & Gong hechun \\
\hline 53. & Male & 31 & Enterprises & Gong hechun \\
\hline 54. & Male & 40 & Enterprises & Gong hechun \\
\hline 55. & Female & 25 & Student & Gong hechun \\
\hline 56. & Female & 30 & Enterprises & Gong hechun \\
\hline 57. & Female & 70 & Retired & Gong hechun \\
\hline 58. & Male & 28 & Enterprises & Gong hechun \\
\hline 59. & Male & 55 & Enterprises & Gong hechun \\
\hline 60. & Female & 32 & Enterprises & Gong hechun \\
\hline 61. & Female & 22 & Student & Gong hechun \\
\hline 62. & Male & 39 & Enterprises & Gong hechun \\
\hline 63. & Male & 62 & Retired & Gong hechun \\
\hline 64. & Male & 31 & Enterprises & Gong hechun \\
\hline 65. & Female & 27 & Enterprises & Gong hechun \\
\hline 66. & Male & 61 & Retired & Gong hechun \\
\hline 67. & Female & 44 & Enterprises & Gong hechun \\
\hline 68. & Female & 37 & Government institutions & Gong hechun \\
\hline & & & & \\
\hline
\end{tabular}




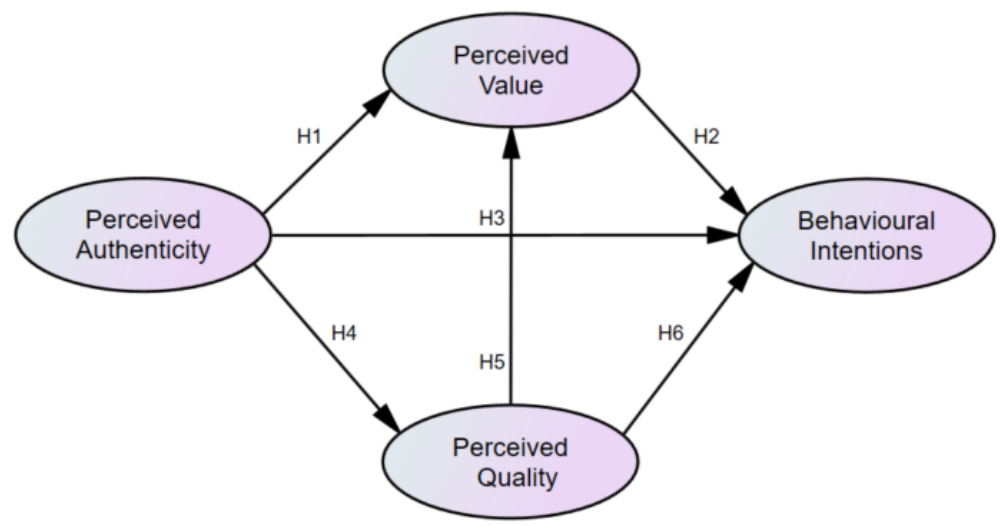

Figure 1. Theoretical Model. 


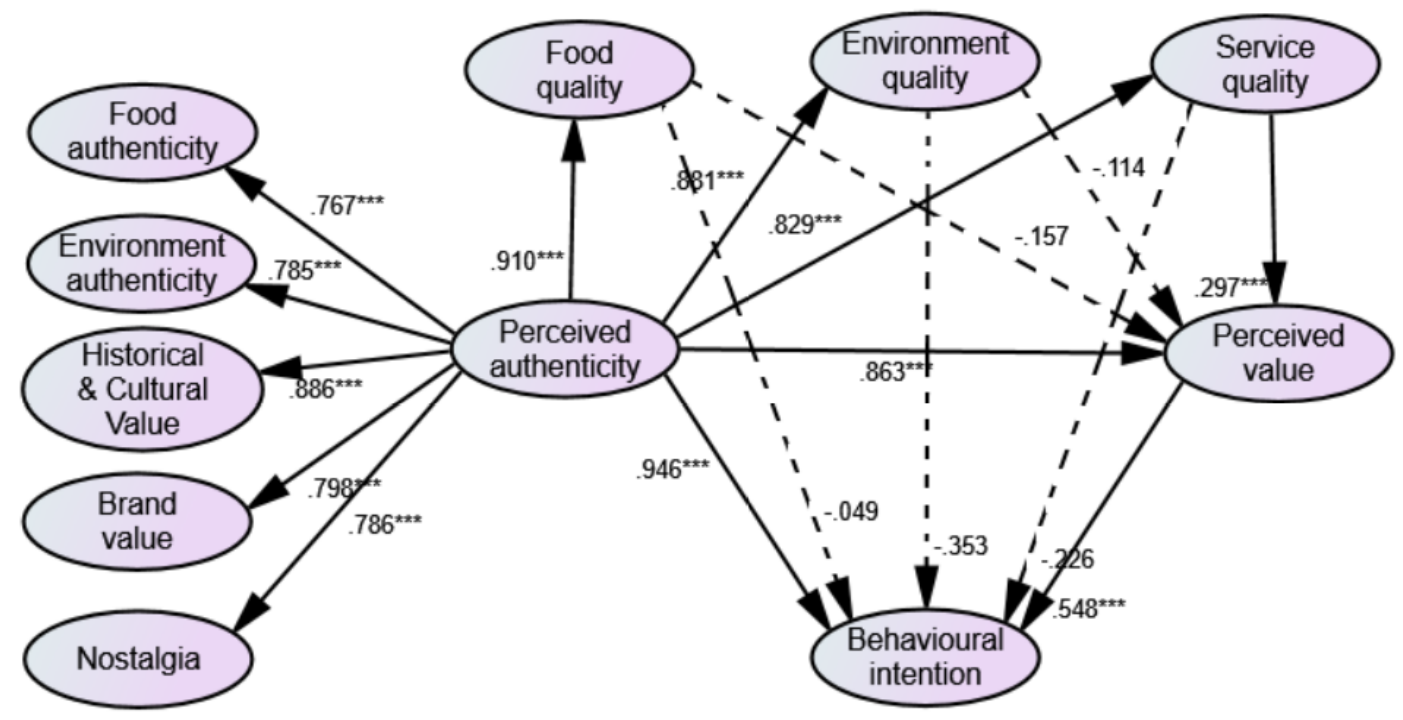

Figure 2. Results of the Structural Model Test.

Note:

$\rightarrow$ Indicates singificant supported path. $\rightarrow$ Indicates non-supported path.

$*$ Significant at $\mathrm{p}<0.10$. $* *$ Significant at $\mathrm{p}<0.05$. $* * *$ Significant at $\mathrm{p}<0.01$ 